\title{
Ethical Leadership and Employee Ethical Behavior: A Moderated Mediation Mechanisms
}

\author{
Muhammad Osaid Rabie (D)*1; Marlin Abdul Malek (D)2 \\ 1,2 Othman Yeop Abdullah Graduate School of Business, Universiti Utara Malaysia \\ * Corresponding author: osaidrabie@gmail.com
}

Article History

Received 2020-03-04

Revised 2020-03-18

Accepted 2020-03-27

Published 2020-03-28

\section{Keywords}

Ethical Leadership

Ethical Behavior

Ethics

Leadership

\section{How to cite?}

Rabie, M. O., \& Malek, M. A. (2020).

Ethical Leadership and Employee Ethical

Behavior: A Moderated Mediation

Mechanisms. SEISENSE Journal of

Management, 3(2), 73-88.

doi:10.33215/sjom.v3i2.321

\section{Abstract}

Purpose- Based on the ongoing unethical scandal in the organizations, this study aims to explain the relationship between ethical leaders and their followers' ethical behavior by explaining the underlying mechanisms.

Design/Methodology- Data were collected through a structured questionnaire from the employees working in companies that produce fast-moving consumer goods. Three hundred sixty-nine samples were taken to study the proposed relationships.

Findings- Results showed ethical leaders positively influence followers. Perceptual and reflective moral attentiveness positively mediates between ethical leadership and ethical behavior of employees. Moral awareness negatively moderates between ethical leadership and followers' ethical behavior via reflective moral attentiveness, whereas moral awareness does not moderate the relationship.

Practical Implications- Following the call for determinants of ethical behavior, this study provides insights for the managers to foster ethical behavior at workplace. 


\section{Introduction}

Leadership in the workplace can influence followers to avoid unethical behaviors; however, despite having ethical compliance programs, organizations are still incurring losses of billions of dollars annually merely due to employees' unethical practices. Recently, scholars have shed light on the losses incurred by organizations just from misreporting and fraudulent activities by employees. For instance, according to Association of Certified Fraud Examiners (2018), organizations suffered a loss of more than $\$ 7$ billion globally merely through misreporting and fraudulent activities. Furthermore, (Lavion, Rivera, \& Elliott, 2018) show that bribery and corruption remained the top causes of loss of billions annually. Over the past decades, scholars have focused on why individuals adopt unethical behavior at the workplace despite having ethical compliance programs. As such, understanding the psychological processes fueling ethical behavior is of both theoretical and practical importance.

Previous studies showed the factors that why individuals adopt unethical behavior or instead engaging in ethical behavior at the workplace. For instance, extant literature sheds light on antecedents of unethical behaviors, abusive supervision (Hannah et al., 2013), moral disengagement (Moore, Detert, Klebe Treviño, Baker, \& Mayer, 2012), moral identity (McFerran, Aquino, \& Duffy, 2010). Consequently, scholars turned their focus towards the drivers of ethical behavior at the workplace, such as codes of conduct (Weaver \& Treviño, 1999), ethical Leadership (Brown \& Treviño, 2006; Brown, Treviño, \& Harrison, 2005; Lu \& Lin, 2014), and ethical climate (Mayer, Kuenzi, \& Greenbaum, 2010). Particularly for ethical leadership, scholars have focused on social values and moral development to promote ethical behavior at work (Brown \& Treviño, 2006). For ethical behavior at the workplace ethical leadership is considered as the most influential factor that can stimulate its followers. This study explores why and when ethical leadership and individuals' characteristics is associated with the tendency to engage in ethical practices.

Recent research has provided insights that explain why and when ethical leaders stimulate their followers to emulate normative behaviors; there is a shortage of research that explains the psychological process from which ethical leaders stimulate their followers' ethical behavior at the workplace. Such psychological insights not only advance the behavioral ethical literature but also provides a different perspective on the employer-employee relationship. Such exploration also allows a better understanding of the chain of causality behind the association among variables (Brown \& Treviño, 2006). For these reasons, current research is going to clarify the chain of effects of ethical leaders on their followers' ethical behavior by proposing multiple mediations and moderated mediation mechanisms. Drawing from social learning theory, the authors posit that ethical leaders stimulate ethical behavior through mediating mechanisms of moral attentiveness (Bandura, 1971).

Further, studies explaining the potential moderator between ethical leadership and ethical behavior are at its infancy, and ethical leadership simulation is mainly dependent on the contextual factors (Moore et al., 2012). For this, studies are now exploring the potential boundary conditions of ethical leadership (Babalola, Stouten, Camps, \& Euwema, 2019; Kalshoven, Den Hartog, \& de Hoogh, 2013). However, quite a few numbers of studies have proposed the moderating relationship between ethical leadership and employees' ethical behavior (Farooq \& Rabie, 2016). Within the social learning theory, the behavior of an individual is a function of individual and environmental influence (Bandura, 1971). Moreover, Bandura (1977) suggests that in observational learning, awareness is important and necessary before an individual model someone's behavior. Therefore, we expect that moral awareness may serve as a potential moderator between ethical leadership and moral attentiveness. Authors suggest that the relationship of ethical leadership with moral attentiveness will become stronger when followers have more awareness of the ethical concerns at the workplace.

This study proposed a moderated mediation model to address our research question (Figure 1). First, following the call of Lu and Lin (2014) to investigate the underlying alternative mediating mechanism through ethical 
leaders influence their followers. We suggest that the ethical behavior of employees gets influenced by ethical leadership via two mediating mechanisms (reflective moral attentiveness, perceptual moral attentiveness). Second, by adding boundary condition, we further posit that moral awareness can be a moderating factor between ethical leadership with reflective and perceptual moral attentiveness. Third, the current study was conducted in a developing world context, the South Asian region, where statistics of unethical behaviors are alarming. This study provides significant insights into the social influence process at the workplace to promote ethical behavior at the workplace.

\section{Literature Review and Hypothesis}

\section{Ethical leadership and followers' ethical behavior}

Social Learning Theory explains to minimize unethical practices at the workplace (Bandura, 1977; Brown et al., 2005). Ethical leadership is defined as "the demonstration of normatively appropriate conduct through personal actions and interpersonal relationships, and the promotion of such conduct to followers through two-way communication, reinforcement, and decision-making" (Brown et al., 2005). They explain ethical leaders are fair, caring, and trustworthy from the employees' perspective. Ethical leaders are considered role models as they make decisions on socially acceptable normative behaviors that can be imitated by their followers (Brown \& Treviño, 2006). Extant literature shows ethical leaders are significantly impacting voice behavior (Qi \& MingXia, 2014), moral judgment (Steinbauer, Renn, Taylor, \& Njoroge, 2014), knowledge sharing behavior (Lei, Do, \& Le, 2019; Lei, Ha, \& Le, 2019) and innovative work behaviors (de Jong \& Den Hartog, 2007). Although existing studies provide insights on the importance of ethical leadership at the workplace, however, the existing body of knowledge is fragmented and silent on the potential contagion effects of ethical leaders; that why and when ethical leaders promote ethicality among followers? (Lu \& Lin, 2014).

In organizations, leaders' behavior creates social norms and behavioral expectations among their followers (Lester, Vogelgesang, Hannah, \& Kimmey, 2010), and such values, expectations, and norms affect the attitudes and behaviors of employees. Individuals at the workplace cannot adopt unethical behavior until and unless they have a feeling that their leaders treat them fairly (Mayer et al., 2010). For these reasons, ethical leaders portray optimistic self and follow their normative behavior, positive reinforcements, and positive characteristics towards stimulating attitudes and behaviors of followers. Therefore, the authors suggest a significant relationship of ethical leadership with ethical behavior as below.

\section{Hypothesis 1: There is a positive relationship between etbical leadership and employee ethical behavior.}

Authors further suggest ethical leaders stimulate followers' ethical behavior through intervening mechanisms of reflective and perceptual moral attentiveness at the workplace.

\section{The mediating role of moral attentiveness}

Moral attentiveness is "the extent to which an individual chronically perceives and considers morality and moral elements in his or her experiences" (S. J. Reynolds, 2008). Concepts related to ethicality can be taken as a cognitive framework that is typically found in the employees having moral attentiveness. Such a mental framework ultimately may lead to the ethical assessment of incoming informational cues from others (S. J. Reynolds, 2008; S. J. Reynolds, Leavitt, \& DeCelles, 2010). From the perspective of Social Learning Theory (Bandura, 1977), followers may adopt the practices of their superiors, and therefore accredit more attention to informational/observational cues and ethical aspects. We suggest that ethical leadership can influence employees' ethical behavior through moral attentiveness because ethical leadership stimulates their followers' attention towards ethical direction by showing them normative behavior to understand and address ethical complexities, concerns, and standards (Zhu, Treviño, \& Zheng, 2016). Individuals having a higher level of 
moral attentiveness are aware of the moral consequences of informational cues, and they are also alerting to ethically charged situations (Culiberg \& Mihelič, 2016; Miao, Eva, Newman, Nielsen, \& Herbert, 2019).

Extant literature shows two components of moral attentiveness: reflective and perceptual moral attentiveness. As far as this facet of moral attentiveness is concerned, reflective moral attentiveness individual regularly considers ethical matters (Miao et al., 2019; S. J. Reynolds, 2008; Whitaker \& Godwin, 2013). Social learning theory within the context of organizations Bandura (1977) argues that as leaders are considered an authority and power symbols in an organization, they are the ones who employees look up, observe and adopt practices. Indulging employees into decision-making based on ethical principles and regularly highlighting the significance of ethics for their behaviors and decisions, employees may start focusing and considering this behavior appropriate that may reflect upon their daily lives (Brown \& Treviño, 2006; Brown et al., 2005)and they are more prone towards ethical behavior at the workplace.

Whereas, in perceptual moral attentiveness, individuals recognize ethical aspects in daily experiences and primarily concerns information coding (S. J. Reynolds, 2008; Whitaker \& Godwin, 2013). At the workplace, ethical leadership creates an ethical climate to minimize misconducts (Mayer et al., 2010), which can generate the perception in the minds of its followers that there are not many chances of occurrence unethical behavior; therefore, employees working under ethical leadership may not be exposed to more ethical challenges because of holding strong ethical standards. This may affect employee's daily experiences, and ultimately this perceptual moral attentiveness leads toward ethical behavior at the workplace.

Moreover, moral attentiveness varies from individual to individual, (M. Reynolds, 1998)and leaders can influence them to increase the level of their moral attentiveness (M. Reynolds, 1998). We posit that ethical leaders can influence their follower's moral attentiveness because of the characteristics they have in their personalities. Ethical leaders are the ones who will regularly communicate with employees regarding their moral dilemmas, set ethical standards, and provide them feedback about ethical decisions. While confronting ethical dilemmas or challenges at the workplace, ethical leaders are the ones who guide and explain their moral values to take action and decisions; they provide insightful and constructive feedback to their employees and provide directions that how to handle such challenges or ethical dilemmas at the workplace. Such a strong focus on dealing with the ethical dilemma at the workplace from ethical leaders, there is a trickle-down effect on employees as they start emulating the practices of their leaders and become more attentive to ethical challenges and dilemmas at the workplace. This is because ethical leaders are credible and legitimate actors in the workplace. Therefore, employees emulate the practices of their leaders in ethical dilemmas and challenges as they are the one whose actions are observed at the workplace, and ultimately leads towards ethical behavior at the workplace. Moreover, ethical leadership seems to be concerned about employees' development and accomplishments and may serve in their best interests (Brown et al., 2005). We argue that employees specifically feel attentive while doing their work by maintaining ethical standards because ethical leader him/herself enacts these ethical standards. As a result, employees become more morally attentive to perform work ethically. It seems that the trickle-down effect of ethical leadership would be better when employees feel confident to behave ethically, allowing moral attentiveness to be viewed as a filter through which such trickledown effect passes. Authors proposed that:

Hypothesis 2a: There is a positive relationship between ethical leadership and perceptual moral attentiveness. Hypothesis 2b: Perceptual moral attentiveness serves as a mediator between ethical leadership and employee ethical behavior. Hypothesis $3 a$ : There is a positive relationship between ethical leadership and reflective moral attentiveness. Hypothesis 3b: Reflective moral attentiveness serves as a mediator between ethical leadership and employee ethical behavior. 


\section{Moral Awareness as a Moderator}

It is “a person's determination that a situation contains moral content, and legitimately can be considered from a moral point of view" (S. J. Reynolds, 2006). Moral awareness is a significant facet of moral decision-making and reasoning (Rest, 1986). It is widely accepted as an antecedent for an individual to teach moral consideration in its cognition. Extant literature on moral awareness suggested that vividness and saliency of any dilemma are the reasons that make individuals consider it as a moral issue. People usually give more consideration to those moral issues that are characterized as salient and vivid (Jones, 1991).

In an organizational context, we posit that when moral awareness among employees at the workplace is higher, there would be less impact on leaders on its followers' ethical behavior. When moral awareness among employees at the workplace is lower, there would be a higher impact of leaders on its followers' ethical behavior. Moreover, if moral awareness is higher, employees would know what is ethical and unethical in a particular situation, and they may have clear thoughts about the proper behavior to be adopted. The more employees are aware of moral issues, the less impact would be taken from their leadership through leaders' modeling and rewarding behavior. Bandura (1977) suggests that attentiveness is remarkable while imitating the behavior of peers. Attention to the desirability towards ethical behavior can be taken from the behaviors of ethical leadership. However, it can be taken if there is a mutual perception of moral awareness. Therefore, if employees are more into moral awareness, they are more into adopting ethical behavior, which may result in them emulating the ethical leaders' behavior for adopting ethical behavior as compared to the situation if there is a low level of moral awareness among employees at the workplace. This relationship is hypothesized belowFigure 1 details the proposed hypotheses.

Hypothesis 4: Moral awareness moderates the mediating effect of perceptual and perceptual moral attentiveness between ethical leadership and followers' ethical behavior that mediating effect of moral attentiveness is weaker when moral awareness orientation is high than when it is low.

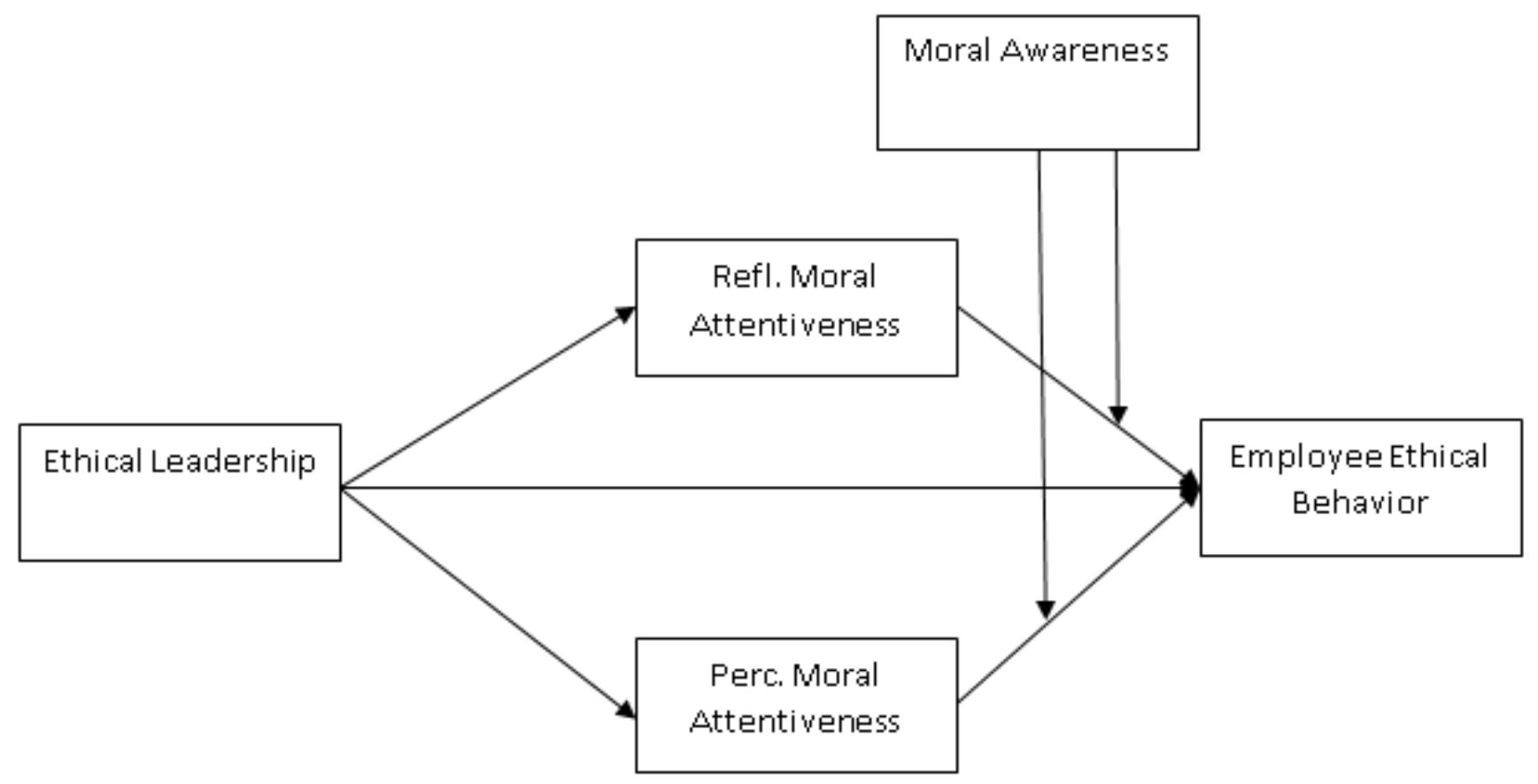

Figure 1 - Theoretical Framework 


\section{Methods}

\section{Sample and Procedure}

The questionnaire was developed for the collection of data from employees of private-sector organizations that manufacture consumer goods in Pakistan. We identified and contacted 22 organizations and contacted their human resource departments to seek approval for data collection after explaining the objectives of our study. Of those 22 companies, 16 were willing to participate in the study, since disclosure of such information indicates involvement in fundamental topical issues. The author personally visited the companies for data collection after getting approval from the HR departments. To reduce the social desirability bias effect, the researcher stressed about confidentiality and anonymity of data, both verbally and through the cover letter that was attached to the questionnaire (Chung \& Monroe, 2003). The response rate from the selected organizations varied from 16\% to $96 \%$. Three hundred eighty-nine responses were successfully gathered; 20 questionnaires have missing values; therefore, they were discarded. The final sample to analyze the data is of 369 employees. Out of 369 respondents, $75 \%$ were male. $69.5 \%$ were less than the age of 40 years. Around $78 \%$ belong to the low functional management positions (lower management), and $22 \%$ of respondents were engaged in functionallevel job responsibilities Table 1.

Table 1 - Demographic Characteristics

\begin{tabular}{lll}
\hline Demographics & & Percentage $\%$ \\
\hline Age & $18-28$ years & 23.5 \\
& $29-40$ years & 46.0 \\
Gender & More than 40 years & 30.5 \\
\multirow{2}{*}{ Education } & Female & 25.0 \\
& Male & 75.0 \\
Management Level & Did not complete Bachelor & 29.0 \\
& Bachelor & 46.0 \\
Job Duration(years) & Master & 25.0 \\
& Non-Management & 78.0 \\
& Lower-Level Management & 22.0 \\
& 0 to 5 & 39.0 \\
\hline
\end{tabular}

\section{Measures}

To measure ethical leadership, authors relied on the ten-item instrument of Brown et al. (2005), as it corresponds to our operationalization of the ethical leadership construct. The instructions asked participants to respond to each item using their manager as the referent. Further, each item referred to the participant's "immediate boss." Employee ethical behavior was measured using Fraedrich (1993) six-item measure. Items are centered around the extent to which observed behaviors complied with or deviated from organizational policies, values, and norms. S. J. Reynolds (2008) five-item scale was used to measure perceptual and reflective moral attentiveness authors adopted S. J. Reynolds (2008) seven-item scale. Moral awareness was measured using Arnaud (2010) 3 item measure of ethical climate index, which is based on the ethical decision model of Rest (1986). 7-point Likert scale used, where $1=$ strongly disagree and $7=$ strongly agree. 


\section{Data Analysis}

\section{Confirmatory Factor Analysis: Validity and Reliability}

For the assessment of measures' validity in the model, the authors performed Confirmatory Factor Analysis (CFA) with AMOS 24. For model validity, we computed three alternative models and compared their level of fit (Anderson \& Gerbing, 1988): First (Table 2), all items were loaded on four constructs as a single factor (Model 1). Second, we computed a three-factor CFA regrouping the three dimensions of CSR in a single construct (Model 2). Finally, we assessed the fit of a five-factor CFA (Model 3). Whereas Models 1 and 2 returned a poor fit (Table 2), the four-factor CFA showed a good fit. The chi-square statistic is 1114.25 having a significance of .000 , and 342 degrees of freedom $\left(\chi^{2} / \mathrm{df}=3.25\right)$, thus indicating a good fit (Kline, 2010). We examined Confirmatory Fit Index (CFI) is .92, and the Tucker-Lewis index (TLI) is .92; both are above their recommended levels of threshold values of 0.90 (Anderson \& Gerbing, 1988; Hair, Anderson, Babin, \& Black, 2010). Additionally, root means square error of approximation (RMSEA) has an acceptable threshold value .08, and CFA in this study showed a value of .07, which is lower. The chi-square difference test Table 2 revealed a five-factor model (Model 3) is good as compared to the alternative models (Model 1 and Model 2).

Table 2 - Alternative models: Model Fits

\begin{tabular}{lllllll}
\hline & \multicolumn{7}{c}{ Fit Indices } \\
\cline { 2 - 7 } Model 1: Single-Factor CFA & $\chi^{2}$ & $\mathrm{df}$ & $\chi^{2} / \mathrm{df}$ & CFI & TLI & RMSEA \\
Model 2: Three-Factor CFA & 6333.06 & 348 & 18.19 & .41 & .41 & .22 \\
Mode1 3: Five-Factor CFA & 2573.92 & 345 & 7.46 & .78 & .78 & .13 \\
\hline
\end{tabular}

$\chi^{2}$ is Chi-square value, $d f$ degree of freedom

Then, to assess convergent validity, the authors assessed standardized regression weights related to all items on their observed factors. Standardized regression weights of items ranged between 0.67 to 0.92. Standardized regression weights higher than .60 establishes a reasonably high factor loading (Kline, 2010). Further assessment for the validity of Fornell and Larcker (1981) of our proposed model, this study adopted the approach of average variance extracted (AVE). The average variance extracted and squared correlations are presented in Table 3. Fornell and Larcker (1981) suggest AVE of each variable must be larger than the recommended value of .50, which is providing support for convergent validity in this study. For the discriminant validity of five factors in our model. We followed Fornell and Larcker (1981) procedure and compared the respective squared correlations between factors with the respective AVEs of the factors. The four constructs are different from each other as their AVE is higher than their squared correlations (see Table 3).

For the reliability of the scales, we relied on Cronbach's alpha. Scales have provided good reliability of the data with values ranging from .89 to .95 (see Table 3), which are higher than .70 threshold value (Nunnally, 1978).

Table 3 - Convergent and discriminant validity

\begin{tabular}{lccccl}
\hline Constructs & $\mathbf{1}$ & $\mathbf{2}$ & $\mathbf{3}$ & $\mathbf{4}$ & Cronbach's Alpha \\
\hline 1. Perceptual Moral Attentiveness & $\mathbf{0 . 7 5}$ & & & & $\mathbf{. 9 5}$ \\
2. Ethical Leadership & 0.32 & $\mathbf{0 . 5 3}$ & & & $\mathbf{. 9 2}$ \\
3. Reflective Moral Attentiveness & 0.37 & 0.39 & $\mathbf{0 . 7 7}$ & & $\mathbf{. 9 4}$ \\
4. Employee Ethical Behavior & 0.46 & 0.39 & 0.40 & $\mathbf{. 6 7}$ & $\mathbf{. 8 9}$ \\
\hline
\end{tabular}

Notes: Bold diagonal values represent the average variance extracted (AVE)

The remaining value represents squared correlations 


\section{Common Method Bias}

Authors used methods of Podsakoff, MacKenzie, Lee, and Podsakoff (2003) for assessing common method bias. To compute Harman's one-factor test, we employed exploratory factor analysis and fixed all variables on one factor, which is $30.79 \%$ of the total variance. Second, for Common Latent Factor (CLF) test, we used CFA and constrained all the items for all dependent and independent variables to load on a single factor, which showed that our model only explained $28.04 \%$ of the common factor, which is under the standard value. Therefore, common method bias in our data is not a severe threat.

\section{Descriptive Statistics: Mean, standard deviation, and correlations}

All components are positively correlated and are also positively associated with employee ethical behavior.

Table 4 - Mean, standard deviation, and correlations

\begin{tabular}{lllllll}
\hline Variables & Mean & St. deviation & 1 & 2 & 3 & 4 \\
\hline 1.Perceptual Moral Attentiveness & 5.29 & 1.24 & & & & \\
2. Ethical Leadership & 4.86 & 1.22 & $.37^{* *}$ & & & \\
3. Reflective Moral Attentiveness & 5.53 & 1.27 & $.35^{*}$ & $.47^{*}$ & \\
4. Employee Ethical Behavior & 5.42 & 1.19 & $.46^{*}$ & $.44^{*}$ & $.43^{*}$ \\
5. Moral Awareness & 3.96 & 1.71 & $-.09^{*}$ & $-.22^{* *}$ & $-.12^{*}$ & $-.15^{* *}$
\end{tabular}

$N=369,{ }^{*} p<.05$.

\section{Hypothesis Testing}

We performed model testing in three steps. In the first step, we measured the direct relationship of independent constructs on dependent constructs. For the second phase, we calculated the specific direct effects by applying the phantom modeling approach Macho and Ledermann (2011) in AMOS 24. The moderated mediation of moral awareness was tested in the third phase using process macro v3.2 in SPSS (Preacher, Rucker, \& Hayes, 2007). Table 6 shows the direct effects of independent variables on dependent variables. It was found during the analysis that ethical leadership has a positive effect on perceptual moral attentiveness $(\beta=.32)$ at a significance level of $<.001)$ and reflective moral attentiveness $(\beta=.39, p<.001)$ of employees at work. Furthermore, we tested the reflective and reflective moral attentiveness as mediators between ethical leaders and their followers' ethical behavior, which showed significant effect on ethical behavior. Significant direct effect provided support to measure the meditating effect between ethical leaders and their followers' ethical behaviors.

Iacobucci, Saldanha, and Deng (2007) stated that it is recommended for mediating analysis that the direct and indirect paths to be checked at the same time so that the estimate of the proposed effect can be obtained while partialling out the effect of other relationships in the model. For this reason, we applied SEM to incorporate the hypothesized indirect effects along with the direct effects of an independent variable on dependent variables. Proposed model showed good fit $\left(\chi^{2}=1333.26, \mathrm{P}<.001 ; \mathrm{df}=345 ; \chi^{2} / \mathrm{df}=3.87 ; \mathrm{CFI}=.90 ; \mathrm{TLI}=0.90\right.$; RMSEA =0.08). However, in pursuit of the best model fit, two alternative models were also tested and compared with the fit indices of the hypothesized model. Alternative models were developed by changing the positions of the two mediators from parallel to series. These alternative models include a double mediation instead of multiple mediations, as in our hypothesized model. The model fits these alternative models (Table 5) indicate that the hypothesized model produces better fit indices. We thus selected our hypothesized model for further interpretation. 
Table 5 - Alternative Model fits

\begin{tabular}{llllllll}
\hline & & Chi-sq & df & $\mathrm{X}^{2} / \mathrm{df}$ & CFI & TLI & RMSEA \\
\hline Theorized SR Model & Model 1 & 1333.26 & 345 & 3.87 & .90 & .90 & .080 \\
Alternative Model 1: & Model 2 & 1410.70 & 347 & 4.06 & .89 & .89 & .090 \\
$\mathbf{E L} \rightarrow$ PMA $\rightarrow$ RMA $\rightarrow$ EB & & & & & & & \\
Alternative Model 2: & Model 3 & 1367.59 & 347 & 3.94 & .90 & .89 & .089 \\
EL $\rightarrow$ RMA $\rightarrow$ PMA $\rightarrow$ EB & & & & & & & \\
\hline
\end{tabular}

The testing of our proposed model shows that all relationships are positively significant, as we hypothesized (Table 6). Results support hypothesis 1, ethical leaders influence followers' ethical behavior in the workplace. Moreover, Ethical leadership positively influences perceived perceptual moral attentiveness and reflective moral attentiveness (Hypothesis $2 \mathrm{a}$ and 3a). Similarly, hypothesis $2 \mathrm{~b}$ and $3 \mathrm{~b}$ are supported by the data as perceived ethical leadership influence employees' ethical behavior via mediating mechanisms of reflective and perceptual moral attentiveness. A significance level of the mediating relationships was calculated with 5000 bootstrap samples in AMOS 24.

\section{Specific Indirect Effects}

As ethical leadership influences employees' ethical behavior through perceptual and reflective moral attentiveness, we are in a classic case of multi-mediation. We, therefore, performed a separate additional analysis to specify the indirect effect of both mediating paths separately (MacKinnon, 2000), which allows comparative analysis of the mediators to provide a better significance of the mediating mechanisms. The phantom model approach addresses this issue in SEM (Macho \& Ledermann, 2011). Results showed the mediating impact of ethical leaders on ethical behavior is positive through perceptual moral attentiveness $(\beta=.33)$ at a significant level of $<.001$ and reflective moral attentiveness $(\beta=.27$ ) at a significance level of $<.001$ (Table 6 ).

Table 6 - Direct and specific indirect effects

\begin{tabular}{|c|c|c|c|c|c|}
\hline \multirow{3}{*}{$\begin{array}{l}\text { Independent } \\
\text { Variable }\end{array}$} & \multicolumn{5}{|c|}{ Dependent Variables } \\
\hline & \multicolumn{3}{|l|}{ Direct Effects } & \multicolumn{2}{|c|}{ Indirect effects on Ethical Behavior } \\
\hline & Perc. Moral & Refl. Moral & Ethical & Via Per. Moral & Via Refl. Moral \\
\hline & Attentiveness & Attentiveness & Behavior & Atten. & Atten. \\
\hline Ethical & $0.32^{* * *}$ & $0.39 * * *$ & $0.22^{* * *}$ & $0.33 * * *$ & $0.27 * * *$ \\
\hline \multicolumn{6}{|l|}{ Leadership } \\
\hline Perc. Moral & & & $0.33^{* * *}$ & -- & -- \\
\hline \multicolumn{6}{|l|}{ Atten. } \\
\hline Refl. Moral & & & $0.21 * * *$ & -- & -- \\
\hline
\end{tabular}

The cell values of the table show the standardized regression weights.

Notes: N: 369

*** Significant at 0.001 


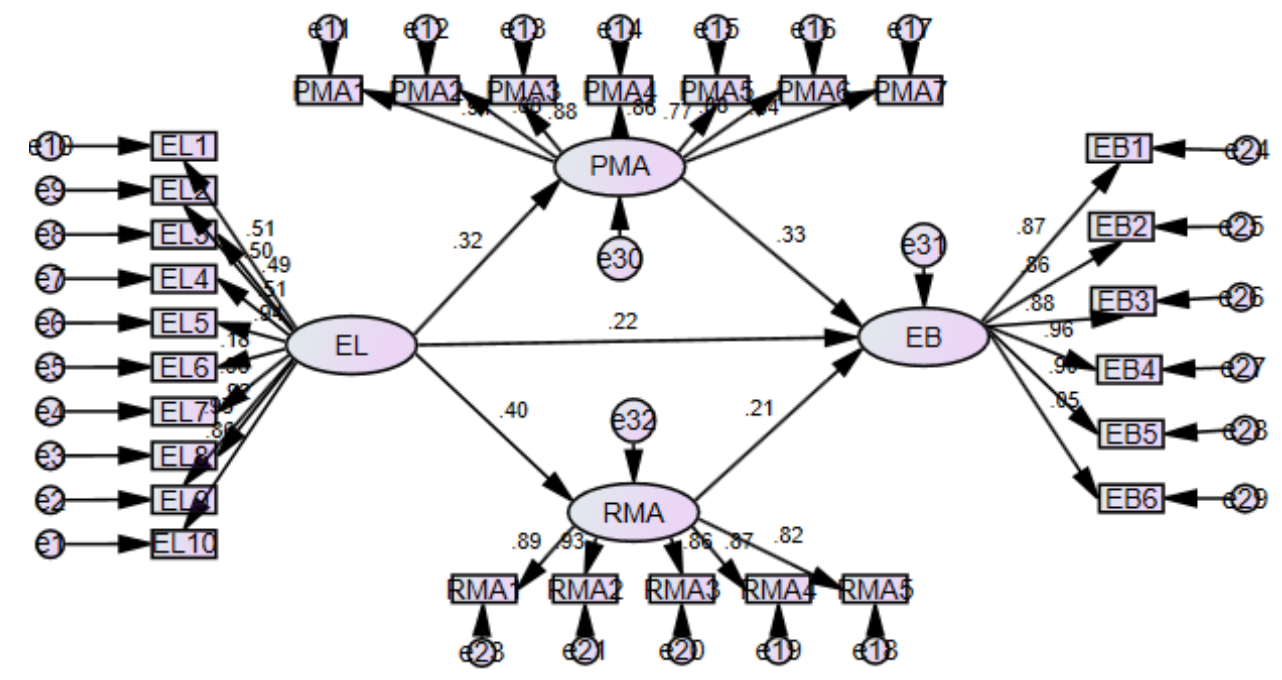

Figure 2 - Structural Regression Model

\section{Moderated Mediation Analysis}

Ethical leaders influence followers' ethical behavior via moral attentiveness. Hypothesis 4 predicts the moderating effect between ethical leadership and ethical behavior through moral attentiveness. However, the mediating effect of moral attentiveness (reflective and perceptual moral attentiveness) was hypothesized to be moderated by moral awareness. Authors used Preacher and Hayes (2008) Process Macro v3.2 to test moderated mediation. Moderated mediation occurs when the conditional mediating mechanism of the independent variable on the variable (via perceptual and reflective moral attentiveness) varies around strength across the high and low level of moderating variable. We tested the moderating variable on conditional indirect paths. Their results are as follows in Table 7.

Table 7 - Moderation of moral awareness on the mediating paths of moral attentiveness

\begin{tabular}{lll}
\hline \multirow{2}{*}{$\begin{array}{l}\text { Moral attentiveness } \\
\text { dimensions }\end{array}$} & Dependent Variable \\
\cline { 2 - 3 } & Independent Variable & Moral Attentiveness \\
\hline \multirow{3}{*}{ Reflective } & Constant & 1.0782 \\
& Ethical Leadership & $0.301^{* * *}$ \\
& Reflective Moral Attentiveness & $0.531^{* * *}$ \\
& Moral Awareness & $0.33^{*}$ \\
& Reflective Moral Attentiveness x Moral Awareness & $-0.063^{*}$ \\
\hline \multirow{3}{*}{ Perceptual } & Constant & $2.9114^{* * *}$ \\
& Ethical Leadership & $0.296^{* * *}$ \\
& Perceptual Moral Attentiveness & $0.236^{*}$ \\
& Moral Awareness & -0.181 \\
\hline
\end{tabular}

$\mathrm{N}=369, * p<0.05, * * * p<0.001$

As is shown in Table 7, moral awareness negatively moderates ethical leaders' influence on followers' ethical behavior via reflective moral attentiveness (hypothesis $4 a$, Figure 2 , interaction value $=-0.06, p<0.05$ ). In other words, ethical leaders influence followers' ethical behavior through reflective moral awareness is weaker when employees are high on moral awareness. However, moral awareness does not moderate between ethical 
leadership and ethical behavior via perceptual moral attentiveness (hypothesis $4 \mathrm{~b}$, interaction value $=0.025$, not significant).

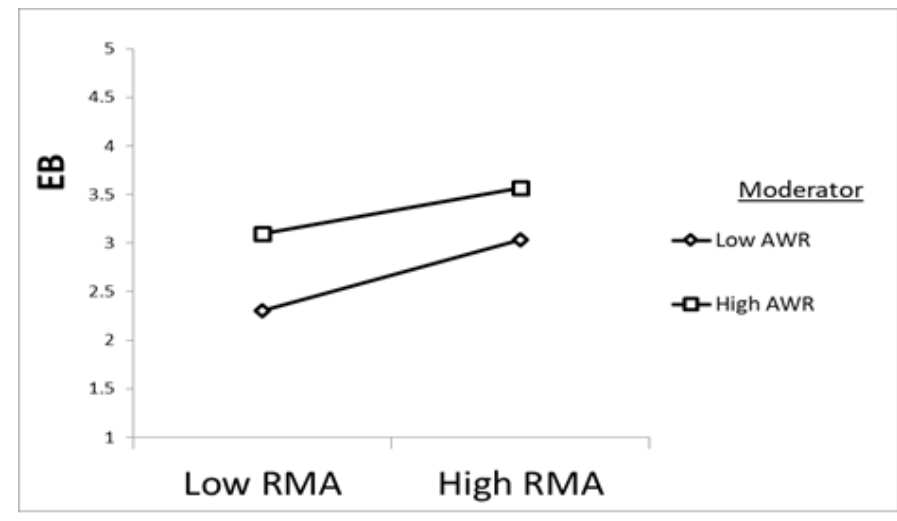

Figure 3 - Moderating Effect

\section{Results and Discussion}

This study integrates social learning theory to explain the multi-mediation (reflective and perceptual moral attentiveness) along with the moderating relationship of moral awareness between ethical leadership and ethical behavior via a moderating mechanism of moral awareness. Using data from South Asia, particularly from Pakistan, the findings of this research revealed that ethical leadership is associated with employees' ethical behavior via mediating mechanisms of reflective and perceptual moral attentiveness whereas, moral awareness of employees determine the strength of these alternative mechanisms (reflective moral attentiveness).

\section{Theoretical Implications}

Traditionally, the scholars were more focused on explaining how ethical leadership influences performancerelated outcomes of employees, such as job performance (Bello, 2012), in-role performance (Zafar, 2013), and extra-role performance (Tu \& Lu, 2016). However, research discussing the effect of ethical leaders on followers' ethical behavior is growing (Lu \& Lin, 2014; Mayer et al., 2010). However, the underlying mechanisms between this relationship need to be further studied. The current study tests the underlying mediating mechanisms to explain why and when ethical leaders influence employees' ethical behavior. Mainly, current research contributes to the body of knowledge by demonstrating multiple mechanisms through which leaders' ethical behavior foster employees' ethical behaviors. That is, ethical leadership induces ethical behavior via moral attentiveness (reflective and perceptual). Through explicating these underlying mediating mechanisms, this research clarifies relationship Preacher and Hayes (2008) of ethical leadership with employees' outcomes, and give clearer insight that enables effective and efficient employees' management (Preacher et al., 2007).

The results complement this study by establishing, perhaps for the first time that moral attentiveness mediates through ethical leadership and ethical behavior. Indeed, ethical leadership literature to date showed that ethical behaviors are being influenced by ethical leadership ( $\mathrm{Lu} \& \mathrm{Lin}, 2014$ ). We are in accordance with Bandura (1977) that moral attentiveness can be increased through efforts to stimulate employees that they entail the capabilities to perform their duties, and it is also supported by previous studies (Walumbwa, Avolio, \& Zhu, 2008; Walumbwa et al., 2011). Results indicate that ethical leaders successfully inculcate trust among employees that they can perform their duties ethically at workplace. It was also noted in the findings that modeling and vicarious experiences are important means in building the moral attentiveness of followers by presenting them as their role models. Ethical leadership provides both modeling and vicarious experiences that mount the moral attentiveness that enables the followers to act ethically at workplace. 
Our results also indicated that ethical leaders have an impact on moral attentiveness that is significant and positive. It is entirely believable that ethical leaders treat their employees by giving them a sense that they are going to address an ethical dilemma by adopting normative behaviors (Brown \& Treviño, 2006). Employees perceive that they will be treated fairly and this also lead employees to adopt such behaviors because they count on their leaders (Mayer, Kuenzi, Greenbaum, Bardes, \& Salvador, 2009), as our findings also support, increases moral attentiveness of employees that ultimately leads towards ethical behavior at the workplace. Moreover, by focusing and reflecting more on ethical issues at the workplace, ethical leadership perceived by their employees as transmitting a critical ethical, emotional, and cognitive connection that enhances their moral attentiveness. Our findings show that through modeling Bandura (1971), ethical leaders become more effective in increasing the moral attentiveness of their followers because employees learn from their leaders by observing and emulating them. Extant literature also shows that moral attentiveness as a moderating variable between ethical leaders with followers' organizational deviance (van Gils, Van Quaquebeke, van Knippenberg, van Dijke, \& De Cremer, 2015). Employees who are high on moral attentiveness, if unethical behavior from their leaders occurs, followers may like to engage in such similar activities. However, in the presence of ethical leadership, they are more into emulating the practices of their ethical leaders because, through perceptual moral attentiveness, employees may better able to understand moral dilemmas at the workplace. As they start perceiving such ethical dilemmas in a real-time situation not only in their daily lives but also in the workplace, they will be more attentive to perform and handle ethical issues by adopting the practices of their leaders.

Our study examines the impact of ethical leadership on employees' ethical behavior via moral attentiveness (reflective and perceptual) but also expands the boundary conditions of these relationships and mechanisms. Specifically, this paper shows that employees were having low moral attentiveness exhibit ethical behavior due to reflective moral attentiveness build from ethical leadership. On the other hand, those who are high on moral attentiveness may not get influenced by the actions of their leaders because they are already aware of handling such dilemmas at the workplace. More precisely, we found that the impact of ethical leadership on ethical behavior via reflective moral attentiveness varies across the low and high value of moral awareness such that at a low level of moral awareness, the indirect effect is higher and at a high level of awareness the indirect effect is weaker.

\section{Practical Implications}

For deeper understating, researchers have called what enhances the employees' ethical behavior at the workplace (Treviño, Weaver, \& Reynolds, 2006). We established that moral attentiveness (reflective and perceptual) is a significant force in enhancing the followers' ethical behavior, and through ethical leadership, they are more prone to adopt normative behaviors. Therefore, firstly, organizations should seek to train or select leaders that embody ethical behavior. For instance, organizations can adopt a variety of tools that appreciate the concern for others' ethical standards and integrity. Such tools may include assessment center exercises, structured interviews, or integrity tests on relevant ethical dilemmas. Investment can be made on the ethical training of managers and leaders. Training could contain agendas, for instance, acting as ethical role models, supporting and rewarding their followers that show ethical behavior or ethical communication.

Consequently, by focusing on and selecting the leaders that embody ethical leadership, organizations can champion and develop ethical leadership values that can simultaneously act as an ethical manager as well as ethical people. Secondly, to increase ethical behavior, organizations should have such leadership that model and encourage ethical behavior along with the systems that restrain unethical behavior and reward ethical conduct. Managers need to practice and promote the procedures that emphasized on the importance of being ethical. Moreover, enforcement of rules and policies that restrain unethical behaviors should be duly enforced to show that organizations are serious about championing ethical conduct in the workplace. 


\section{Future Directions and Limitations}

We expected several limitations because of the quantitative and exploratory nature. First, cross-sectional design was employed due to which we are not able to induce certain conclusions because of the nature of constructs. Furthermore, employing single-source data, the threat of common method bias can arouse in the analysis. Due to the model complexity, multi-source, or experimental design was neither feasible nor practiced. We followed Podsakoff et al. (2003) to handle such issues, we incorporated different approaches for common method variance, we tested common latent factor (CLF), which showed that common method variance was not a serious threat. It was not likely to bias the outcomes of the research. Therefore, we recommend that future studies should conduct experiments to develop more robust causal conclusions. Second, due to social desirability bias, all of the self-reported items could be contaminated. We took confidentiality assurances to our respondents to deal with this preventively (Chung \& Monroe, 2003). Further, self-reporting was most suitable in the context of this research because constructs in this study involved perceptual variables.

\section{Conclusion}

The current study has enlightened the prominence of ethical leadership that the leadership drives their followers to behave ethically or unethically at the workplace by acting as their role models. We, however, suggested a new perspective that explains the impact ethical leaders have on their follower's ethical behavior. Results showed that ethical leadership has a significant impact on followers' ethical behavior via perceptual and reflective moral attentiveness. Furthermore, moral awareness found to have a moderating effect between ethical leadership and followers' ethical behavior. Current research provides insights for managers to implement ethical compliance programs and to adopt normative practices to influence their followers to act ethically.

Funding: This research received no external funding.

Conflicts of Interest: The authors declare no conflict of interest.

\section{References}

Anderson, J. C., \& Gerbing, D. W. (1988). Structural equation modeling in practice: A review and recommended two-step approach. Psychological Bulletin, 103(3), 411-423. doi:10.1037/0033-2909.103.3.411

Arnaud, A. (2010). Conceptualizing and Measuring Ethical Work Climate: Development and Validation of the Ethical Climate Index. Business \& Society, 49(2), 345-358. doi:10.1177/0007650310362865

Babalola, M. T., Stouten, J., Camps, J., \& Euwema, M. (2019). When Do Ethical Leaders Become Less Effective? The Moderating Role of Perceived Leader Ethical Conviction on Employee Discretionary Reactions to Ethical Leadership. Journal of Business Ethics, 154(1), 85-102. doi:10.1007/s10551-017-3472$\mathrm{Z}$

Bandura, A. (1971). Social learning theory. Morristown. In: NJ: General Learning Press.

Bandura, A. (1977). Self-efficacy: Toward a unifying theory of behavioral change. Psychological Review, 84(2), 191215. doi:10.1037/0033-295X.84.2.191

Bello, S. M. (2012). Impact of ethical leadership on employee job performance. International Journal of Business Social Science, 3(11).

Brown, M. E., \& Treviño, L. K. (2006). Ethical leadership: A review and future directions. The Leadership Quarterly, 17(6), 595-616. doi:10.1016/j.leaqua.2006.10.004

Brown, M. E., Treviño, L. K., \& Harrison, D. A. (2005). Ethical leadership: A social learning perspective for construct development and testing. Organizational Behavior and Human Decision Processes, 97(2), 117-134. doi:10.1016/j.obhdp.2005.03.002

Chung, J., \& Monroe, G. S. (2003). Exploring social desirability bias. Journal of Business Ethics, 44(4), $291-302$. 
Culiberg, B., \& Mihelič, K. K. (2016). Three ethical frames of reference: insights into Millennials' ethical judgements and intentions in the workplace. Business Ethics: A European Review, 25(1), 94-111. doi:10.1111/beer.12106

de Jong, J. P. J., \& Den Hartog, D. N. (2007). How leaders influence employees' innovative behaviour. European Journal of Innovation Management, 10(1), 41-64. doi:10.1108/14601060710720546

Examiners, A. o. C. F. (2018). About the Association of Certified Fraud Examiners and the Report to the Nations on Occupational Fraud and Abuse. In Profiling the Fraudster (pp. 239-242). Hoboken, NJ, USA: John Wiley \& Sons, Inc.

Farooq, M., \& Rabie, O. (2016). How and When Does Ethical Leaders Institutionalize its Followers. Academy of Management Proceedings, 2016(1), 17162. doi:10.5465/ambpp.2016.17162abstract

Fornell, C., \& Larcker, D. F. (1981). Structural Equation Models with Unobservable Variables and Measurement Error: Algebra and Statistics. Journal of Marketing Research, 18(3), 382-388. doi:10.1177/002224378101800313

Fraedrich, J. P. (1993). The ethical behavior of retail managers. Journal of Business Ethics, 12(3), 207-218. doi:10.1007/BF01686448

Hair, J., Anderson, R., Babin, B., \& Black, W. (2010). Multivariate data analysis: A global perspective (Vol. 7): Pearson Upper Saddle River. In: NJ.

Hannah, S. T., Schaubroeck, J. M., Peng, A. C., Lord, R. G., Trevino, L. K., Kozlowski, S. W. J., . . Doty, J. (2013). Joint influences of individual and work unit abusive supervision on ethical intentions and behaviors: A moderated mediation model. Journal of Applied Psychology, 98(4), 579-592. doi: $10.1037 /$ a0032809

Iacobucci, D., Saldanha, N., \& Deng, X. (2007). A Meditation on Mediation: Evidence That Structural Equations Models Perform Better Than Regressions. Journal of Consumer Psychology, 17(2), 139-153. doi:10.1016/S1057-7408(07)70020-7

Jones, T. M. (1991). Ethical Decision Making by Individuals in Organizations: An Issue-Contingent Model. Academy of Management Review, 16(2), 366-395. doi:10.5465/amr.1991.4278958

Kalshoven, K., Den Hartog, D. N., \& de Hoogh, A. H. B. (2013). Ethical leadership and followers' helping and initiative: The role of demonstrated responsibility and job autonomy. European Journal of Work and Organizational Psychology, 22(2), 165-181. doi:10.1080/1359432X.2011.640773

Kline, R. (2010). edition 3. Principles and practice of structural equation modeling. In: New York. The Guilford Press.

Lavion, D., Rivera, K., \& Elliott, S. (2018). Pulling fraud out of the Shadows: Global Economic Crime and Frand Survey 2018. Retrieved from https://pwc. com/.../global-economic-crime-and-fraud-survey--summary-inf

Lei, H., Do, N. K., \& Le, P. B. (2019). Arousing a positive climate for knowledge sharing through moral lens: the mediating roles of knowledge-centered and collaborative culture. Journal of Knowledge Management, 23(8), 1586-1604. doi:10.1108/JKM-04-2019-0201

Lei, H., Ha, A. T. L., \& Le, P. B. (2019). How ethical leadership cultivates radical and incremental innovation: the mediating role of tacit and explicit knowledge sharing. Journal of Business \& Industrial Marketing, aheadof-print(ahead-of-print). doi:10.1108/JBIM-05-2019-0180

Lester, P. B., Vogelgesang, G. R., Hannah, S. T., \& Kimmey, T. (2010). Developing courage in followers: Theoretical and applied perspectives. In C. L. S. Pury \& S. J. Lopez (Eds.), The psychology of courage: Modern research on an ancient virtue. (pp. 187-207). Washington: American Psychological Association.

Lu, C.-S., \& Lin, C.-C. (2014). The Effects of Ethical Leadership and Ethical Climate on Employee Ethical Behavior in the International Port Context. Journal of Business Ethics, 124(2), 209-223. doi:10.1007/s10551-013-1868-y

Macho, S., \& Ledermann, T. (2011). Estimating, testing, and comparing specific effects in structural equation models: The phantom model approach. Psychological Methods, 16(1), 34-43. doi:10.1037/a0021763 
MacKinnon, D. P. (Ed.) (2000). Contrasts in multiple mediator models: In J. Rose, L. Chassin., CC Presson, \& SJ Sherman (Eds.) Multivariate applications in substance use research ( $p$ p. 141-160).

Mayer, D. M., Kuenzi, M., Greenbaum, R., Bardes, M., \& Salvador, R. (2009). How low does ethical leadership flow? Test of a trickle-down model. Organizational Behavior and Human Decision Processes, 108(1), 1-13. doi:10.1016/j.obhdp.2008.04.002

Mayer, D. M., Kuenzi, M., \& Greenbaum, R. L. (2010). Examining the Link Between Ethical Leadership and Employee Misconduct: The Mediating Role of Ethical Climate. Journal of Business Ethics, 95(S1), 7-16. doi:10.1007/s10551-011-0794-0

McFerran, B., Aquino, K., \& Duffy, M. (2010). How Personality and Moral Identity Relate to Individuals' Ethical Ideology. Business Ethics Quarterly, 20(1), 35-56. doi:10.5840/beq20102014

Miao, Q., Eva, N., Newman, A., Nielsen, I., \& Herbert, K. (2019). Ethical Leadership and Unethical ProOrganisational Behaviour: The Mediating Mechanism of Reflective Moral Attentiveness. Applied Psychology, apps.12210. doi:10.1111/apps.12210

Moore, C., Detert, J. R., Klebe Treviño, L., Baker, V. L., \& Mayer, D. M. (2012). WHY EMPLOYEES DO BAD THINGS: MORAL DISENGAGEMENT AND UNETHICAL ORGANIZATIONAL BEHAVIOR: PERSONNEL PSYCHOLOGY. Personnel Psychology, 65(1), 1-48. doi:10.1111/j.17446570.2011.01237.x

Nunnally, J. C. (1978). Psychometric Theory: $2 d$ Ed: McGraw-Hill.

Podsakoff, P. M., MacKenzie, S. B., Lee, J.-Y., \& Podsakoff, N. P. (2003). Common method biases in behavioral research: A critical review of the literature and recommended remedies. Journal of Applied Psychology, 88(5), 879-903. doi:10.1037/0021-9010.88.5.879

Preacher, K. J., \& Hayes, A. F. (2008). Contemporary Approaches to Assessing Mediation in Communication Research. In The SAGE Sourcebook of Advanced Data Analysis Methods for Communication Research (pp. 1354). 2455 Teller Road, Thousand Oaks California 91320 United States: Sage Publications, Inc.

Preacher, K. J., Rucker, D. D., \& Hayes, A. F. (2007). Addressing Moderated Mediation Hypotheses: Theory, Methods, and Prescriptions. Multivariate Behavioral Research, 42(1), 185-227. doi:10.1080/00273170701341316

Qi, Y., \& Ming-Xia, L. (2014). Ethical leadership, organizational identification and employee voice: examining moderated mediation process in the Chinese insurance industry. Asia Pacific Business Review, 20(2), 231248. doi:10.1080/13602381.2013.823712

Rest, J. R. (1986). Moral development: Advances in research and theory.

Reynolds, M. (1998). Reflection and critical reflection in management learning. Management Learning, 29(2), 183200. doi:10.1177/1350507698292004

Reynolds, S. J. (2006). Moral awareness and ethical predispositions: Investigating the role of individual differences in the recognition of moral issues. Journal of Applied Psychology, 91(1), 233-243. doi:10.1037/0021-9010.91.1.233

Reynolds, S. J. (2008). Moral attentiveness: Who pays attention to the moral aspects of life? Journal of Applied Psychology, 93(5), 1027-1041. doi:10.1037/0021-9010.93.5.1027

Reynolds, S. J., Leavitt, K., \& DeCelles, K. A. (2010). Automatic ethics: The effects of implicit assumptions and contextual cues on moral behavior. Journal of Applied Psychology, 95(4), 752-760. doi:10.1037/a0019411

Steinbauer, R., Renn, R. W., Taylor, R. R., \& Njoroge, P. K. (2014). Ethical Leadership and Followers' Moral Judgment: The Role of Followers' Perceived Accountability and Self-leadership. Journal of Business Ethics, 120(3), 381-392. doi:10.1007/s10551-013-1662-x

Treviño, L. K., Weaver, G. R., \& Reynolds, S. J. (2006). Behavioral ethics in organizations: A review. Journal of Management, 32(6), 951-990. 
Tu, Y., \& Lu, X. (2016). Do Ethical Leaders Give Followers the Confidence to Go the Extra Mile? The Moderating Role of Intrinsic Motivation. Journal of Business Ethics, 135(1), 129-144. doi:10.1007/s10551014-2463-6

van Gils, S., Van Quaquebeke, N., van Knippenberg, D., van Dijke, M., \& De Cremer, D. (2015). Ethical leadership and follower organizational deviance: The moderating role of follower moral attentiveness. The Leadership Quarterly, 26(2), 190-203. doi:10.1016/j.leaqua.2014.08.005

Walumbwa, F. O., Avolio, B. J., \& Zhu, W. (2008). How transformational leadership weaves its influence on individual job performance: the role of identification and efficacy beliefs. Personnel Psychology, 61(4), 793825. doi:10.1111/j.1744-6570.2008.00131.x

Walumbwa, F. O., Mayer, D. M., Wang, P., Wang, H., Workman, K., \& Christensen, A. L. (2011). Linking ethical leadership to employee performance: The roles of leader-member exchange, self-efficacy, and organizational identification. Organizational Behavior and Human Decision Processes, 115(2), 204-213. doi:10.1016/j.obhdp.2010.11.002

Weaver, G. R., \& Treviño, L. K. (1999). Compliance and Values Oriented Ethics Programs: Influenceson Employees' Attitudes and Behavior. Business Ethics Quarterly, 9(2), 315-335. doi:10.2307/3857477

Whitaker, B. G., \& Godwin, L. N. (2013). The Antecedents of Moral Imagination in the Workplace: A Social Cognitive Theory Perspective. Journal of Business Ethics, 114(1), 61-73. doi:10.1007/s10551-012-1327-1

Zafar, A. (2013). Linking Ethical Leadership and Employees' In-Role Performance: Exploring the Mediating roles of Psychological Capital and Follower-Leader Relational Capital.

Zhu, W., Treviño, L. K., \& Zheng, X. (2016). Ethical Leaders and Their Followers: The Transmission of Moral Identity and Moral Attentiveness. Business Ethics Quarterly, 26(1), 95-115. doi:10.1017/beq.2016.11 